\title{
SOCIAL, CULTURAL, AND RELIGIOUS ASPECT IN MOSQUE FUNDRAISER
}

Aspek Sosial, Budaya dan Keagamaan pada Peminta Sumbangan Masjid

\author{
Achmad Naufal Irsyadi ${ }^{1,}$, Fachriana Hanifiyah ${ }^{2,}$, , Suryadi ${ }^{3,}$, \\ ${ }^{1}$ Universitas Nurul Jadid \\ Probolinggo, Indonesia \\ 2 UIN Maulana Malik Ibrahim \\ Malang, Indonesia \\ 3 UIN Sunan Ampel \\ Surabaya, Indonesia \\ *E-mail: naufalirsyadiachmad@gmail.com
}

\begin{abstract}
This study described and analyzed the form and types of speech in fundraising activity as well as to identify social, cultural, and religious aspect in it. The observation was carried out in Wirolegi Village, Sumbersari District, Jember Regency. This study used a phenomenological perspective which viewed that fundraising activity was a social reality known by the public. This study used anthropolinguistic approach which viewed that people's linguistics activities (speech) were related to the social and cultural systems of the community. To examine the forms and types of speech, this study used Searle's speech act theory. This study resulted a finding that the utterances of the fundraiser were about expressive and commissive speech acts. Thus, the language activity within fundraising program was an action that was clearly and indirectly contained in his speech. In its social aspect, the speech contained a binding from the speaker to the interlocutor which could contribute to their social and religious aspect.
\end{abstract}

Keywords: Language as action, Searle's speech act, culture, social, religion

Abstrak: Studi ini mendeskripsikan dan menganalisis bentuk dan jenis tuturan Peminta sumbangan, serta mengidentifikasi aspek sosial, budaya, dan keagamaan yang terkandung di dalamnya. Pengamatan dilakukan di Desa Wirolegi, Kecamatan Sumbersari, Kabupaten Jember. Studi ini menggunakan perspektif fenomenologi yang memandang aktivitas Peminta sumbangan merupakan suatu realitas sosial yang diketahui oleh masyarakat. Studi ini menggunakan pendekatan antropolinguistik yang memandang bahwa aktivitas bahasa masyarakat memiliki keterkaitan dengan sistem sosial dan budaya pada masyarakat itu. Untuk meneliti bentuk dan jenis tuturan, studi ini menggunakan teori tindak tutur Searle. Studi ini menghasilkan sebuah temuan bahwa tuturan Peminta sumbangan mengandung unsur tindak tutur ekspresif dan komisif. Dengan demikian, aktivitas berbahasa saat melaksanakan kegiatan "meminta sumbangan" merupakan sebuah aksi yang secara jelas dan tidak langsung terkandung dalam tuturanya. Dalam aspek sosial, tuturannya mengandung pengikat dari petutur ke lawan tutur yang dapat memberikan kontribusi dan kebermanfaatan sosial dan agama antara kedua pihak (petutur dan lawan tutur).

Kata Kunci: Bahasa sebagai aksi, tindak tutur Searle, budaya, sosial, agama

\section{PENDAHULUAN}

Pada hakikatnya, kebudayaan merupakan seluruh aktivitas berpikir, berkreasi, dan tingkah laku seseorang dalam suatu kelompok sosial dan daerah. 
Kebudayaan tidak hanya mencakup praktik fisik dan olah cipta manusia dalam suatu daerah dan dalam sebuah kelompok etnis, melainkan juga pola pikir yang terlaksana dalam bentuk tindakan yang berkelanjutan (Mahadi \& Jafari, 2012). Kebudayaan juga dapat berupa praktik cipta secara lisan maupun tulisan, baik verbal maupun non-verbal, sehingga usaha pendefinisian kebudayaan bersifat luas dan tidak ada batasan.

Istilah budaya lebih berorientasi pada bentuk aktivitas kebudayaan secara konkret, sedangkan kearifan lokal lebih identik dengan nuansa dan nilai yang terkandung dalam aktivitas kebudayaan. Nilai tersebut terdiri atas nilai sosial, nilai keagamaan, dan nilai lainnya yang bermanfaat bagi kehidupan hidup masyarakat dalam sebuah komunitas kebudayaan. Nilai sosial-keagamaan adalah satu-satunya nilai yang menjadi citra dan esensi dari sebuah kebudayaan dan kearifan lokal.

Peminta sumbangan (Bahasa Inggris; fundraiser) merupakan istilah sederhana yang merujuk pada sebuah aktivitas dimana beberapa orang saling tolong-menolong melakukan aktivitas sosial, yaitu menggalang dana untuk kepentingan pembangunan bersama. Fenomena semacam ini dapat kita temukan di daerah pedesaan ataupun kecamatan yang cenderung dilintasi oleh kendaraan umum (Zalikha, 2016). Aktivitas sosial semacam ini melibatkan berbagai macam keunikan yang bisa kita lihat, mulai dari bagaimana seorang pembicara memandu jalannya proses Peminta sumbangan dengan melantunkan berbagai aktivitas linguistik seperti bernyanyi, bersholawat, hingga memanjatkan do'a.

Peminta sumbangan juga sering ditemui di daerah timur Jawa Timur. Biasanya, aktivitas sosial ini dilaksanakan untuk meminta sumbangan dana untuk pembangunan dan pengembangan bangunan masjid sebagai tempat beribadah. Penelitian mengenai Peminta sumbangan diteliti dan dikaji oleh beberapa penelitian dari berbagai pendekatan keilmuan, yaitu pendekatan sosial-antropologi (Mustaqim, 2020), konstruksi sosial (Holis, 2017; Zalikha, 2016), manajemen (Nashar, 2018), manajemen keuangan syariah (Fahmi, 2017), dan ekonomi-agama (Saleh et al., 2014).

Studi ini meneliti aspek sosial-budaya, dan keagamaan dalam fenomena Peminta sumbangan sebagai sebuah fenomena bahasa. Studi ini meyakini bahwa ada pertautan antara aspek sosial, budaya, dan keagamaan dalam aktivitas tutur Peminta sumbangan.

Pengambilan objek kajian ini berlandaskan pada paradigma bahasa Malinowski yang mengatakan bahwa "the main function of language is not to express thought, not to duplicate mental processes, but rather to play an active pragmatic part in human behavior" (Duranti, 1997: 239).

\section{METODE}

Studi ini mengkaji nilai sosial-budaya, dan keagamaan Peminta sumbangan masjid sebagai sebuah fenomena kebahasaan dalam lingkungan masyarakat lokal. Studi ini menggunakan paradigma fenomenologi, karena studi ini meneliti bahasa sebagai salah satu bentuk kebudayaan masyarakat dan termasuk dalam jenis fenomena sosial.

Menurut Huesserl, fenomenologi merupakan sebuah sudut pandang yang memandang sebuah fenomena sebagai suatu realitas yang tampak di hadapan 
manusia (Hasbiansyah, 2008). Peminta sumbangan merupakan aktivitas (fenomena) sosial yang tampak di lingkungan masyarakat lokal, sehingga diperlukan sebuah pendekatan. Dikarenakan fokus studi ini adalah aktivitas berbahasa Peminta sumbangan, maka pendekatan yang tepat adalah pendekatan Antropolinguistik. Dalam hal ini, fenomena kebahasaan Peminta sumbangan dikaitkan dengan aspek sosial-budaya dan faktor eksternal lainnya seperti unsur keagamaan di dalamnya.

Untuk memudahkan analisis fenomena kebahasaan Peminta sumbangan, maka studi ini menggunakan teori Tindak Tutur Searle serta teori bahasa sebagai aksi (language as action).

Studi ini dilakukan di Kecamatan Wirolegi Kabupaten Jember pada tahun 2019 dengan melakukan teknik perekaman untuk mengambil data mengenai tuturan Peminta sumbangan. Kemudian, data dianalisis berdasarkan teori dan pendekatan yang digunakan dalam studi ini.

\section{HASIL}

Konsep utama dalam teori Tindak Tutur adalah bahwa ketika seseorang mengatakan sesuatu, ia secara tidak langsung melakukan sesuatu. Dari penjelasan tersebut, dapat diketahui bahwa Tindak Tutur merupakan suatu pendekatan teoretis terhadap fenomena kebahasaan seseorang untuk meneliti dan mengetahui fungsi ujarannya. Karena, pada hakikatnya penutur tidak selalu mengatakan apa yang dimaksudkan dalam tuturannya (Apriastuti, 2017). Dalam teori Tindak Tutur Searle, dikenal beberapa istilah seperti komisif, deklaratif, ekspresif, direktif, serta asertif. Beberapa istilah tersebut mengacu pada fungsi tuturan seseorang, sehingga untuk mengetahui pengaruh ataupun implikasi sosial tuturannya, dapat kita gunakan konsep dasar Perlokusi dalam kajian Tindak Tutur.

Fenomena Peminta sumbangan merupakan fenomena yang melibatkan aktivitas kebahasaan. Berdasarkan hasil pengamatan, ditemukan bahwa setidaknya dua jenis tuturan yang terkandung dalam tuturan pemandu proses Peminta sumbangan, yaitu ekspresif dan komisif.

Dalam tutur ekspresif, ada dua kecenderungan pemandu proses Peminta sumbangan dalam mengajak setiap orang untuk ikut berkontribusi, yaitu thanking dan praising. Dalam artian, si pemandu Peminta sumbangan setidaknya tidak luput dari tuturan yang mengandung ucapan terima kasih dan pujian terhadap setiap orang yang memberi sebagaimana tuturan berikut:

\section{Tuturan 1:}

“Adduh ... Kaso'on ghi Dek ghi. Mandher mugheh usahanah e parengih kelancaran. Amal ibadah panjhenengan semoga dikabulkan di hadapan Allah Subhanahu Wata'ala. Amin Allahumma Aminn ..."

(Aduh ... Terimakasih ya Dek ya. Semoga usahanya diberikan kelancaran. Amal ibadahnya semoga dikabulkan di hadapan Allah SWT. Amin Allahumma Amin ...)

\section{Tuturan 2:}

"Terimakasih Mas, selamat jalan dari arah barat menuju arah timur. Mobil mewah" 


\section{Tuturan 3:}

"Alhamdulillah ... Alhamdulillah ... Alhamdulillah engghi ... Alhamdulillah ... mandher mugheh beres selamet klaben kesehatan dheri gusteh Allah. Sadhejeh tan-tretan Muslimin Muslimat roda duwe' roda empa' dheri temor dheri bhere', perjalanan penjhenengan neng pos amal masjid Babussalam e parengih kelancaran. Mohon selamat perjalanan pulang pergi sampe' di rumah Anda masing-masing. Amin ..."

(Alhamdulillah ... Alhamdulillah ... Alhamdulillah ya... Alhamdulillah ... semoga sehat dan selamat serta diberikan kesehatan oleh gusti Allah. Semua saudarasaudaraku Muslimin Muslimat roda dua roda empat yang dari timur dari barat, perjalanan Anda di pos Amal masjid Babussalam diberikan kelancaran. Mohon selamat perjalanan pulang pergi sampai rumah Anda masing-masing)

Ketiga contoh di atas merupakan kutipan dari rekaman suara pemandu proses Peminta sumbangan yang dilaksanakan di daerah Wirolegi Jember. Dari ketiga contoh tersebut, kita dapat melihat bahwa pemandu proses Peminta sumbangan tidak hanya mengatakan rasa terima kasihnya atas sumbangsih warga sekitar maupun para pengguna jalan yang melewati pos Amal mereka. Mereka bahkan mendo'akan mereka dengan do'a yang sesuai dengan apa yang telah mereka berikan.

Dengan gaya bahasa santunnya serta pemilihan katanya, seseorang akan secara tidak langsung terpanggil untuk memberikan sumbangan ekonomi kepada Peminta sumbangan. Dengan demikian, prinsip kesopanan dan prinsip kebahasaan yang mereka gunakan dapat menjadi pegangan utama mereka dalam melaksanakan dan mencapai tujuan bersama, yaitu pembangunan masjid.

Selain Tindak Tutur ekspresif, pemandu proses Peminta sumbangan secara tidak langsung juga menggunakan tindak tutur komisif dalam hal penawaran (offering). Hal ini terlihat dalam tuturan di bawah ini:

\section{Tuturan 1:}

“Monggo ... barangkali Anda punya keikhlasan membantu kami, yaa monggo amalnya silahkan ... lemparkan saja ..."

\section{Tuturan 2:}

“Yatoreh, pola tan-tretan ka' dintoh se terro amal ghi. Ka tokang beca'enh pon pareng aghi. Ampon siap menerima amal epon panjhenengan e long mapolong aghi untuk membantu demi lancarnya pembangunan masjid Babussalam ..."

(Mari, Silahkan. Mungkin saudara-saudara ini ingin beramal. Berikan ke tukang becaknya. Sudah siap menerima amal Anda yang dikumpulkan untuk membantu demi lancarnya pembangunan masjid Babussalam)

Dua kutipan tuturan di atas merupakan contoh dari tindak tutur komisif yang mengandung arti bahwa pemandu proses meminta sumbangan juga mengajak orang-orang sekitar dan para pengguna jalan untuk memberikan sumbangan materialnya terhadap pembangunan masjid. Hal ini serupa dengan penelitian yang dilakukan oleh Istiqamah (2017) yang menemukan bahwa tindak 
tutur komisif dilakukan dengan tidak adanya paksaan dan intimidasi dari petutur kepada lawan tutur. Selain itu, dalam dua kutipan tuturan tersebut, pemandu Peminta sumbangan tidak melupakan unsur kesantunan atau kesopanan dalam berbahasa, terlebih ketika mengajak orang-orang sekitar ataupun pengguna jalan untuk beramal. Penggunaan bahasa Madura krama masih terlihat dalam tuturan tersebut, seperti kata "Yatoreh, aghi, ka' dintoh, panjhenengan".

Dalam sudut pandang Malinowski tentang bahasa, bahasa (tuturan) tidak selalu berarti sebuah tuturan saja, melainkan sebuah tindakan (Arvianti, 2011). Dalam konteks Peminta sumbangan, aktivitas berbahasa saat melaksanakan kegiatan "meminta sumbangan" merupakan sebuah aksi yang secara jelas dan tidak langsung terkandung dalam tuturannya. Dalam aspek sosial, tuturannya mengandung pengikat dari petutur ke lawan tutur yang dapat memberikan kontribusi dan kebermanfaatan sosial dan agama antara kedua pihak (petutur dan lawan tutur).

Pada akhirnya, jelas bahwa Peminta sumbangan sebagai kegiatan kemasyarakatan dapat dikatakan sebagai potret sosial masyarakat di Jawa Timur-an khususnya daerah timur Jawa Timur dan Tapal Kuda. Dari potret sosial tersebut, dapat diidentifikasi aspek sosial, budaya, dan keagamaan. Dengan pembawaan dan muatan linguistiknya, nilai kebudayaannya dapat diperkuat, terlebih dengan adanya unsur kemasyarakatan yang terkandung dalam proses pelaksanaannya.

\section{PEMBAHASAN}

Kebudayaan pada dasarnya merupakan hasil cipta dan hasil ide manusia yang tertuang ke dalam bentuk aktivitas. Dalam hal ini, Koentjaraningrat sebagai bapak Antropologi Indonesia memberlakukan beberapa konsep mengenai kebudayaan nusantara, sehingga untuk mengatakan bahwa suatu bentuk kegiatan merupakan sebuah wujud kebudayaan bangsa Indonesia perlu untuk diperbandingkan dengan konsep kebudayaan nusantara. Koentjaraningrat merumuskan beberapa prinsip kebudayaan nasional yang terkandung dalam kebudayaan masyarakat dan bangsa Indonesia, antara lain sistem mata pencaharian, sistem kemasyarakatan, bahasa, kesenian, sistem religi, dan sistem pengetahuan (Sumarto, 2019).

Fenomena Peminta sumbangan merupakan suatu fenomena yang sering kita temukan di daerah-daerah Jawa Timur-an, khususnya di daerah timur Jawa Timur, di mana terdapat banyak populasi dari masyarakat Madura. Dalam pelaksanaannya, setidaknya ada dua peran yang dimainkan oleh masyarakat yang berpartisipasi dalam kegiatan sosial yang dikenal dengan istilah Peminta sumbangan tersebut. Dua peranan tersebut adalah si pembicara atau pemandu dan penerima uluran tangan masyarakat sebagai penyumbang dana. Dikarenakan penyebarannya dan kemasyhurannya di kalangan masyarakat Madura, maka Peminta sumbangan dapat dikatakan sebagai fenomena sosial masyarakat (Holis, 2017). Fenomena tersebut terdiri atas dan ditopang oleh aktivitas Bahasa sebagai media komunikasi.

Dalam prinsip kebudayaan nasional, bahasa menjadi salah satu prinsip yang tertanam dan terkandung dalam kebudayaan nasional. Fenomena Peminta sumbangan merupakan fenomena sosial yang melibatkan peranan bahasa dalam 
pelaksanaannya. Bahasa yang digunakan dalam pelaksanaan Peminta sumbangan, dalam sudut pandang Sosiolinguistik merupakan ragam bahasa informal yang cenderung menciptakan nuansa keakraban dalam tuturannya. Para partisipan dalam kegiatan Peminta sumbangan semacam ini membentuk suatu kebiasaan atau dapat disebut juga kebudayaan dengan melibatkan ulah bahasa yang berbeda dengan kebanyakan ragam bahasa lainnya.

Selain bahasa, sistem kemasyarakatan juga merupakan salah satu prinsip dalam kebudayaan nasional yang dapat kita temukan dalam fenomena Peminta sumbangan. Dengan melihat dan berkonsentrasi pada latar belakang dan alasan pelaksanaan Peminta sumbangan, maka dapat diketahui bahwa ada tuntutan sosial dan bersama yang membuat suatu kelompok sosial dalam suatu daerah melakukan aktivitas meminta sumbangan.

Penelitian yang dilakukan oleh Holis (2017) di Kabupaten Pamekasan menemukan bahwa fenomena peminta sumbangan masjid dilakukan atas ketidakpercayaan masyarakat kepada pengelola masjid, maka dapat dikatakan bahwa Peminta sumbangan dilaksanakan atas kepentingan bersama, bukan pribadi masing-masing. Kebanyakan, Peminta sumbangan diadakan untuk mempermudah pembangunan masjid, tempat-tempat umum, serta infrastruktur masyarakat lainnya melalui sumbangsih ekonomi. Dengan demikian, proses Peminta sumbangan mengandung unsur kemasyarakatan dan nilai kemasyarakatan dalam pelaksanaannya.

Dalam pelaksanaan Peminta sumbangan, terdapat fenomena kebahasaan yang digunakan dalam beragam fungsi, salah satu di antaranya adalah untuk mendapatkan perhatian dari masyarakat lainnya yang tidak berpartisipasi dalam kegiatan Peminta sumbangan. Perhatian tersebut ditandai dengan adanya sumbangsih yang mereka dapat dari mereka yang merasa empati. Keempatiannya dapat disebabkan oleh dua hal, yaitu dikarenakan ia benar-benar merasa empati dan berjiwa sosial, dan dikarenakan mereka berkeinginan untuk mendapatkan Do'a barokah oleh pemandu Peminta sumbangan. Oleh karena itu, aktivitas kebahasaan Peminta sumbangan diteliti dengan menggunakan teori tindak tutur Searle untuk melihat jenis dan fungsi tuturan. Di sini, Bahasa dipandang sebagai sesuatu yang tidak hanya bersifat konvensional dan deskriptif, melainkan sebagai alat pengikat sosial (Roza, 2015).

\section{KESIMPULAN}

Peminta sumbangan tidak hanya berdiri sebagai aktivitas kemasyarakatan biasa, melainkan fenomena kebahasaan yang di dalamnya terkandung aspek sosial, budaya, dan agama. Dari hasil analisis, diperoleh bahwa Peminta sumbangan nyatanya bermuatan unsur kebudayaan, yaitu bahasa dan sistem kemasyarakatan yang di dalamnya dibangun nilai sosial yang tinggi. Dengan demikian, dalam membangun suatu unsur kebudayaan tersebut, bahasa menjadi penguat unsur kebudayaan yang ada dalam peminta sumbangan. Selain itu, dalam pengamatannya, ditemukan bahwa pola-pola serta sistem kebahasaan seperti tindak tutur dan prinsip kesantunan (kesopanan) terlihat dalam tuturan yang dituturkan oleh pemandu Peminta sumbangan. Peminta sumbangan memiliki kecenderungan perlokusi yang mampu membuat orang-orang untuk menyalurkan tangannya. Dengan demikian, secara garis besar, kita dapat 
mengambil kesimpulan bahwa bahasa tidak hanya berfungsi sebagai penyampai pikiran, melainkan memiliki peran dalam menciptakan efek pragmatis dalam kehidupan sosial.

\section{DAFTAR PUSTAKA}

Apriastuti, N. N. A. A. (2017). Bentuk, Fungsi dan Jenis Tindak Tutur dalam Komunikasi Siswa Di Kelas IX Unggulan SMP PGRI 3 Denpasar. Jurnal Ilmiah Pendidikan Dan Pembelajaran, 1(1), 38-47.

Arvianti, I. (2011). Kajian Konteks dalam Tindakan Tutur Tidak Langsung. Majalah Ilmiah INFORMATIKA, 2(1), 68-81.

Duranti, A. (1997). Lingusitic Anthropology. Cambridge University Press.

Fahmi, R. A. (2017). Manajemen Keuangan Masjid di Kota Yogyakarta. Al-Tijary: Jurnal Ekonomi Dan Bisnis Islam, 3(1), 69-86.

Hasbiansyah, 0. (2008). Pendekatan Fenomenologi: Pengantar Praktik Penelitian dalam Ilmu Sosial dan Komunikasi. Mediator, 9(1), 163-180.

Holis, M. (2017). Jurnal Konstruksi Masyarakat Pencari Sumbangan di Jalan Raya (Studi Kasus Pencarian Amal Masjid di Jalan Raya Kabupaten Pamekasan). Universitas Muhammadiyah Malang.

Istiqamah. (2017). Kesantunan Berbahasa dalam Tindak Tutur pada Buku Cerita Anak Abangku Sayangkarya Marion. Jurnal Retorika, 10(2), 73-78.

Mahadi, T. S. T., \& Jafari, S. M. J. (2012). Language and Culture. International Journal of Humanities and Social Science, 2(17), 230-235.

Mustaqim, M. (2020). Pergeseran Perilaku Wama-Wama (Studi atas Para Pencari Sedekah di Kecamatan Bonang Demak). Jurnal Studi Agama Dan Masyarakat, 16(01), 1-9.

Nashar. (2018). Wajah Masjid di Madura (Studi Historis dan Sosiologis Dinamika Manajemen Masjid dalam Pemberdayaan Ummat. Nuansa, 15(2), 333-364.

Roza, A. S. (2015). Teori Pembelajaran Bahasa (Suatu Catatan Singkat). Garudhawaca.

Saleh, K., Riyanto, R., \& Mustaqim, M. (2014). Tradisi Mengemis: Pergulatan antara Ekonomi dan Agama: Studi Perilaku Mengemis Masyarakat di Demak. Jurnal Penelitian, 8(1), 23-44.

Sumarto. (2019). Budaya, Pemahaman dan Penerapannya: Aspek Sistem Religi, Bahasa, Pengetahuan, Sosial, Kesenian dan Teknologi. JURNAL LITERASIOLOGI, 1(2), 144-159.

Zalikha. (2016). Pemberian Sumbangan Kepada Para Peminta-Minta Pasca Panen Padi. Jurnal Al-Bayan, 22(33), 82-100. 